\title{
El nuevo orden económico internacional. Tendencias observables en el norte y en los países mayores de América Latina
}

UN POCO DE HISTORIA...

Desde la ya legendaria conferencia de Bandung (1955) hasta la actualidad, el eje de interés de los países en desarrollo en sus relaciones con los países industrializados se ha ido desplazando del anticolonialismo y la no alineación frente a las superpotencias —asuntos políticos-, a crecientes exigencias de modifiçaciones en el orden mundial tendientes a colocar los temas relacionados con el desarrollo —asuntos económicosen el primer plano de la agenda internacional.

El momento histórico fundamental que produce un profundo cambio en la autopercepción de los países en desarrollo respecto de su poder y de su rol en las negociaciones internacionales, es la decisión de la OPEP de cuadruplicar los precios del petróleo en 1973. La más inmediata de sus consecuencias importantes fue la aprobación, el $1^{\circ}$ de mayo de 1974, por la Asamblea General de Naciones Unidas, al término de la $6^{a} \mathrm{Se}-$ sión Especial, de dos resoluciones tituladas: "Declaración sobre el Establecimiento de un Nuevo Orden Económico Internacional" y "Programa de Acción para el Establecimiento de un Nuevo Orden Económico Internacional".

Las demandas esenciales del mundo en desarrollo contenidas en este programa consistían en: mejores condiciones de acceso de sus productos manufacturados a los mercados del Norte, precios estables para sus materias primas, renegociación de sus deudas públicas, restricciones a las actividades de las empresas transnacionales y mejores condiciones de acceso a sus tecnologías, creciente participación en la producción industrial mundial, mayor transferencia de recursos reales en condiciones concesionarias para financiar el desarrollo, y una mayor voz en el manejo del sistema monetario internacional y en las instituciones financieras internacionales.

La reacción del Norte, en especial de Estados Unidos y Alemania, fue en principio negativa y hostil. Sin embargo, las características globales de los aspectos involucrados en la agenda y la cohesión, inesperada por muchos, del bloque Sur en torno a la exigencia de no separar, tal como 
pretendía Estados Unidos, las negociaciones de los asuntos energéticos de los otros temas económicos, produjo un cambio de estrategia por parte de los países industrializados.

Así, en septiembre de 1975 Henry Kissinger, en un discurso que fue leído por el embajador Moynihan ante la Asamblea General de Naciones Unidas en su $7^{a}$ Sesión Especial, indicó la voluntad de Estados Unidos de conversar sobre una amplia gama de asuntos económicos. De este modo, el debate se trasladó de la confrontación y el desafío a un más genuino "diálogo" Norte-Sur".

Ambos bloques adoptaron una resolución mediante la cual fijaron un marco para desarrollar futuras negociaciones en siete áreas claves: comercio internacional, transferencia de recursos y reforma monetaria, ciencia y tecnología, industrialización, alimentación y agricultura, cooperación entre países en desarrollo y reestructuración de los sectores económico y social del sistema de las Naciones Unidas. Este éxito del Sur y la trabajosa aceptación del Norte tuvieron como trasfondo, y en gran parte como sustento, las nuevas condiciones que ofrecía la economía internacional:

a) Politización del tema económico desde el comienzo de la década del setenta por la creciente importancia del factor económico en las relaciones internacionales, y como consecuencia lógica de la creciente desilusión de muchos líderes del Sur respecto de la doctrina neoliberal que dejaba librada la asignación de recursos a escala mundial a las manos "invisibles" pero injustas del mercado".

b) Brusca disminución de los ritmos de crecimiento que caracterizaron el período 1945-1972 e incertidumbre acerca de sus tendencias.

c) Proliferación del poder económico mundial caracterizada por la erosión de la hegemonía norteamericana sobre el sistema capitalista internacional y el ascenso de Alemania y Japón, la emergencia de algunos países de la clase media internacional con pretensiones de jugar un rol diferenciado en las relaciones económicas mundiales y la multiplicación de las fuentes de abastecimiento de los bienes de capital, financiamiento y tecnología ${ }^{3}$.

${ }^{1}$ Gf. Mc. Laughlin, Martin M., "The United States and the North-South Dialogue: A Survey" en Mc. Laughlin, Martin M. and the Staff of The Overseas Development Council, The United States and World Development: Agenda 1979, New York, Praeger Publishers for the Overseas Development: Council, pp. 77 y 78.

${ }^{2}$ Sobre la politización del tema económico véase Knorr, Klaus, Economic Interdependence and National Security, y Gilpin, Robert Economic Interdependence and National Security in Historical Perspective, en Knorr, Klaus y Trager, Frank N. ed., Economic Issues and National Security; Karisas, Regents Press, 1977.

${ }^{3}$ Sobre el tema de la proliferación del poder económico mundial ver, entre otros, a: 
d) Creciente interdependencia a nivel global y en especial a nivel del sistema trilateral (Estados Unidos, Comunidad Económica Europea y Japón.) que provocó "la internacionalización de la política económica nacional de los países integrantes del sistema"'4 .

e) Persistencia de amplios niveles de pobreza en el mundo en desarrollo.

f) Amenaza de mermas en el suministro de petróleo y de otros recursos naturales ${ }^{5}$.

Estas condiciones, que brindaron mayores márgenes de maniobra autónoma al bloque Sur, y su extraordinaria cohesión, a pesar de los intentos cooptacionistas del Norte respecto de los países más pobres no productores de petróleo (Cuarto Mundo), impulsaron nuevos avances. Con la creación de la Conferencia Internacional de Cooperación Económica de París en el año 1975, el diálogo Norte-Sur entró en una etapa más formal de negociaciones.

Sin embargo, el consenso obtenido durante la Séptima Sesión especial de la Asamblea General de las Naciones Unidas demostró ser más retórico que real; en realidad, esta Conferencia produjo, en su primer año, escasos logros y puso de relieve la existencia de profundos desacuerdos tanto entre ambos bloques como intrabloques.

Dentro del Norte las posiciones abarcaron un amplio espectro, en cuyos extremos se encontraron por un lado Estados Unidos y Alemania, que fueron los más reacios a "ceder", y en el otro los países escandinavos y Holanda, más proclives a aceptar tesis "acomodacionistas". En el medio quedaron Japón y el resto de los países industrializados de Europa Occidental, quienes, por su tremenda vulnerabilidad frente al petróleo, se vieron forzados a adoptar posiciones más eclécticas.

Por su parte, en el seno del bloque Sur, y preanunciando algunas tendencias, hubo importantes diferencias entre los países más radicalizados (Argelia) y los moderados / conservadores. La actitud fría de Brasil, México y Corea del Sur frente al tema de la moratoria de la deuda pública de los países en desarrollo, es el ejemplo más nítido de lo que acabamos de mencionar ${ }^{6}$.

Ferrer, Aldo, La Comisión Trilateral y la proliferación. del poder económico internacional, Buenos Aires, Academia Nacional de Ciencias Económicas, 1979; y Riefman, Alfred, The International Economy, Overvew, en The U.S. Role in a changing World Political Economy: Major Issues for The $96^{\text {th }}$ Congress, Washington, U.S. Government Printing Office, 1979.

${ }^{4}$ Ferrer, Aldo, ob. cit., p. 12.

${ }^{5}$ Una breve explicación de los puntos e) y 7 puede verse en Reifman, Alfred, ob. cit., pp. 8 y 9.

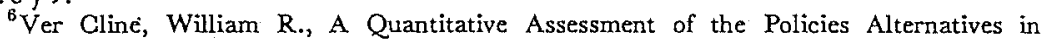
the NIEO Negotiations, en Cline, William R. ed., policy Alternatives for a New International 
A pesar de este estancamiento, el triunfo de James Carter en las elecciones norteamericanas de 1976, generó esperanzas en varios líderes del Sur, quienes creyeron que el nuevo gobierno demócrata impulsaría importantes medidas en el terreno de la cooperación y el diálogo entre los países industrializados y los países en desarrollo.

Se llegó incluso a postergar, hasta marzo de 1977, la Conferencia de París, las negociaciones sobre el Fondo Común y las tratativas individuales sobre productos básicos "para permitir que la nueva Administración Cärter pudiera participar en ellas, y capitalizar así la promesa de cambio que el nuevo liderazgo parecía ofrecer" ${ }^{\prime \prime 7}$.

En efecto, la nueva administración llegó a la Casa Blanca basada en una percepción del mundo caracterizada por intereses globales, la comprensión de los cambiọs ocurridos en la jerarquía de la estructura del poder internacional, el reconocimiento de la mutualidad de intereses entre los países de un mundo cada vez más interdependiente, y la creencia de que los conflictos existentes podían resolverse por métodos distintos al del empleo de la fuerza. Utilizando la terminología del profesor -Stanley Hoffmann; podríamos decir que partió de la toma de conciencia de que el mundo había pasado de un sistema internacional con primacía norteamericana a un orden mundial ("world order") marcado por la difusión del poder económico y político ${ }^{8}$.

Esta filosofía globalista y cooperativa del nuevo gobierno ha sido perfectamente caracterizada por Robert Tucker en-un reciente artículo: "Fue este punto de vista el que alentó la conclusión de que la Administración Carter estaba orientada hacia el futuro relevante, en contraste con Kissinger quien quedaba sumido en un pasado irrelevante. La expresión política principal de este contraste fue el énfasis puesto por la Administración Carter en la importancia de las relaciones NorteSur. Kissinger había dejado su puesto más preocupado que nunca con las relaciones Este-Oeste y con su centralidad a la política norteaericana. Sus sucesores anunciaban su intención de cambiar la prioridad de las preocupaciones de Kissinger y no era sorprendente que así lo hicieran, ya que la relación Norte-Sur, entre países desarrollados y países en desarrollo, era la que parecía caber mejor dentro de sus puntos de vista. Por contraste, las relaciones con la Unión Soviética se acomodaban mal

Economic Order. An Economic Analysis, New York, Praeger, 1979, pp. 8 y 9. Ver también Cooper, Richard N., A New International Economic Order For Mutual Gain, en Foreign Policy, $N^{\circ} 26$, Spring 1977, pp. 74 y 75.

${ }^{7}$ Mc. Laughlin, Martin M. ob. cit., p. 78.

${ }^{8}$ Véase Hoffmann, Stanley, Primacy or World Order. American Foreign Policy since the Cold War, New York, Mc. Graw-Hill, 1978, en especial capítulos 3 y 6. 
dentro de él. Las relaciones Norte-Sur evocaban la necesidad de políticas de "orden mundial". Las relaciones Este-Oeste recordaban a las políticas de "balance del poder". Como tales, eran una especie de atavismo residual, en oposición cada vez mayor con las fuerzas que estaban alcanzando ascendencia en el nuevo sistema global ${ }^{\prime 9}$.

Esta concepción del mundo amplió necesariamente y de una manera inédita el foco de la política exterior de Estados Unidos; como consecuencia de ello el gobierno demócrata fijó varias metas prioritarias que debían cumplirse simultáneamente:

a) Superación de la crisis del espíritu -estimulada por la guerra de Vietnam y la crisis nacional y constitucional de Watergate-.. y promoción de los derechos humanos.

b) Estabilización del equilibrio militar con la Unión Soviética (apoyo a la detente, negociación de acuerdos sobre limitación de armamentos estratégicos, etc.).

c) Contribución al establecimiento de un sistema mundial más amplio y cooperativo, cuyo eje central sería "una comunidad segura y económicamente cooperativa de las democracias induștriales" asegurar un funcionamiento ordenado y estable de esa comunidad se percibía como imprescindible la adopción de políticas complementarias que apuntaran al mejoramiento de las relaciones con los principales Estados emergentes del Tercer Mundo, incluso, cuando fuera posible, con los países comunistas (Cuba, China y Europa Oriental).

d) Resolución de conflictos regionales que amenazaban la paz regional y la estabilidad mundial (ej.: Canal de Panamá, Medio Oriente, etc.).

e) Inauguración de políticas y programas para tratar temas relacionados con la proliferación nuclear, la transferencia de armamentos convencionales, el desarrollo económico y el diálogo Norte-Sur ${ }^{1}$. Respecto a este último tema, el propio Brzezinski admitió, en 1977: "estamos tratando de crear un nuevo orden político internacional en el que haya verdaderamente más participación y que responda más auténticamente al deseo mundial de mayor justicia social, equidad y más oportunidad para el desarrollo in dividual ${ }^{312}$.

\footnotetext{
9Tucker, Robert W. America in Decline: The Foreign Policy of "Maturity", en Foreign Affairs, America and the World 1979, Vol. $58 \mathrm{~N}^{\circ} 3,1980$, p. 463.

${ }^{10}$ Brzezinski, Zbigniew, Prioridades de la política exterior de los Estados Unidos, en Facetas, Vol. 11, N 3,1978, p. 63.

${ }^{11}$ Ver Huntington, Samuel P., The U.S. Goverriment and International Relations, ponencia presentada en la denominada Conferencia Atlántica, Bahía, Brasil, 1978, mimeo, p. 19.

${ }^{12}$ Brzezinski, Zbigniew, ob. cit., p. 63.
} 
Para cumplir estos objetivos, la nueva administración adoptó una posición nueva frente al proceso de cambio mundial en el que pretendía jugar un rol constructivo, abandonando la tradicional política de Estados Unidos de defensa del statu quo, que le valiera innumerables críticas de parte de aliados y enemigos. "Nos propusimos deliberadamente identificar a los Estados Unidos con la noción de que el cambio es un fenómeno positivo, que creemos que. el cambio se puedé canalizar construtivamente, y que el cambio internacional puede ser compatible con nuestros propios valores espirituales fundamentales ${ }^{213}$. Esta concepción del cambio, "de ser relevantes al proceso", a la que Tucker calificó como la "preocupación dominante" de la Administración Carter, apuntaba, frente a un mundo sin primacías, a evitar el aislamiento norteamericano de las naciones y sus pueblos. Respecto de los países más pobres, se pensaba, por ejemplo, que una presencia norteamericana importante en la forma de ayuda, comercio e inversiones, durante bos años formativos del desarrollo nacional, generaría un casi indestructible sistema de alianzas y evitaría el crecimiento de enemistades históricas o políticas en ese mundo ${ }^{14}$.

Esta plataforma exterior del nuevo gobierno alentó, y no casualmente, esperanzas de profundas modificaciones respecto de la actitud de Estados Unidos frente al NOEI, ya que ella parecía encajar perfectamente en el marco de los fundamentos filosóficos que sustentaban ese programa de reformas al orden existente.

Sin embargo, a cuatro años de la Asunción de Carter, podemos apreciar que el supuesto nuevo rol de Estados Unidos - y el resto de los países del mundo industrializado - no ha producido ni siquiera mínimamente los cambios esperados. Cabe preguntarse, entonces, por qué no ha sido así. Los párrafos que siguen pretenden justamente, contestar este interrogante.

\section{EstanCAMcENTO EN EL NORTE Y EN EL SUR}

En estos seis años transcurridos desde la reunión de la Sexta Sesión Especial de la Asamblea General de Naciones Unidas, mucho se ha escrito y, aún más, discutido, acerca de las implicancias y contenidos reales del NOEI, visión que proyecta distintas luces y sombras según la ubicación política e incluso geográfica del observador ${ }^{15}$.

\footnotetext{
${ }^{13}$ Ibíd. p. 62.

${ }^{14}$ Ver Hughes, Kent. U.S. Policy Toward Developing Countries, en the U.S. Role in a Changing World Political Economy, ob. cit., p. 73.

${ }^{15}$ Russell Roberto y Carballal Teresa, América Latina ¿Hacia qué nuevo orden in-
} 
Poco importa analizar aquí si el NOEI es esencialmente un "approach económico liberal-reformista"16 0 , en el fondo, sólo una "idea profundamente occidental" ${ }^{317}$ del cambio, basada en la convicción de que la humanidad puede atacar de una manera sistemática y con éxito la pobreza del mundo, o en realidad una modificación profunda en las estructuras del arden actual ${ }^{18}$.

Nuestro interés en esta parte del trabajo consiste en centrar la óptica en las causas del actual estancamiento. Como diría Denoon, trataremos de averiguar cuál ha sido la combinación de factores que convirtieron al NOEI de una avalancha en un avance glacial ${ }^{19}$.

En primer término, marcaremos los aspectos que en ambos bloques han constreñido las posibilidades de avance en la temática que nos ocupa. A continuación analizaremos las tendencias en el Norte, en especial las observables en Estados Unidos poniendo el acento en las estrategias privilegiadaś en la actual coyuntura respecto del mundo en desarrollo, fundamentalmente la dirigida a los países intermedios, aspecto este último que, junto a las formas de reacomodamiento de estos países al sistema económico internacional, constituye el objetivo central de este trabajo.

\section{Problemas en el Norte}

Desde la perspectiva del mundo industrializado, los elementos que básicamente han incidido en forma negativa en el "enfriamiento" del diálogo han sido la crítica situación económica mundial, y sus incidencias sobre las economías desarrolladas, el agravamiento de la tensión EsteOeste $y$, aunque en menor medida, las modalidades internas del funcionamiento del sistema político norteamericano.

ternacional? en Tomassini Luciano y Hill Eduardo, ed., América Latina y el Nuevo Orden Económico Internacional, Santiago, CPU, 1979, pp. 139-164.

${ }^{16}$ Sauvant, Karl P., The New International Economic Order: Towards Structural Changes or a More Tolerable Status Quo?, en Finger, Seymour Maxwell and Harbert, Joseph R., ed., V.S. Policy in International Institutions: Defining Reasonable Options in an Unreasonable World, Boulder, Colorado, Westview Press, 1978, p. 137'.

${ }^{17}$ Cooper, Richard N., ob. cit., pp. 72 y 73.

${ }^{18} U_{n}$ excelente análisis sobre las diversas posiciones respecto del diálogo Norte-Sur puede verse en Hansen, Roger D., Beyond The Nort-South Stalemate, New York, Mc. Graw-Hill, 1979, en especial capítulos 3, 6, 7 y 8.

${ }^{19}$ Denoon, David B.H., Facing the New International Economic Order en Denoon David B.M. ed., The New International Economic Order A.U.S, Reiponse, New York, New York Unventy Press, 1979, p. 15. 
La Situación Económica Mundial y sus incidencias en los paises desarrollados

Los problemas económicos que enfrenta el mundo industrializado imponen fuertes constreñimientos a los asuntos relacionados con la temática del NoEI. No cabe duda que la preocupación fundamental de las élites dirigentes del Norte, consiste en asegurar un funcionamiento estable y cooperativo entre sus países.

Este objetivo pudo complimentarse sin demasiados inconvenientes hasta los primeros años de la década del 70 . Desde el inicio de la recuperación económica europea y japonesa hasta 1973, las tensiones existentes se manejaron dentro de un contexto caracterizado por el crecimiento económico, el pleno empleo y la expansión del comercio internacional.

A partir del receso de 1974/75 este panorama ha variado sustancialmente. La "administración controlada" de los problemas económicos intranorte debió efectuarse dentro de un contexto caracterizado por el desempleo, la inflación y el crecimiento lento. "Consecuentemente, el proceso de ajuste de los desequilibrios de los pagos internacionales se ha hecho más dificil y, lo que es más grave, han surgido demandas proteccionistas que amenazan con derrumbar el orden dentro del cual se ha gestado y expandido el Sistema Trilateral ${ }^{220}$.

En consecuencià ese orden liberal de economías abiertas y los sistemas nacionales que lo componen, se hallan sometidos a importantes oscilaciones causadas esencialmente por factores económicos externos, debido a la creciente interdependencia existente entre los países del mundo industrializado ( $y$ en menor medida a la que tiene lugar entre ellos y algunos países del Sur). De esta forma las tensiones en el Norte, se han incrementado de manera inédita ya que sus economías son hoy más "sensibles" o "vulnerables" que nunca a los impactos externos".

A pesar de su enorme trascendencia escapa a nuestro objetivo analizar qué rumbo seguirá el Norte frente a estos desafíos. Si buscará salir de la crisis a través de mecanismos multilaterales remozados de cooperación, - si favorecerá como parece ser el caso, el surgimiento de un nuevo mercantilismo $^{22}$, que se muestra en el largo plazo como sumamente

${ }^{20}$ Ferrer, Aldo, ob. cit, p. 18.

${ }^{21}$ Acerca de la diferencia entre la interdependencia de sensibilidad y vulnerabilidad, véase el importante libro de Kheoane, Robert O. y Nye, Joseph S., Power an Intrdependence, Boston, Little Brown and Company, 1977, Primera Parte.

${ }_{22}^{22}$ De acuerdo con Roger Hansen, el término neömercantiliano se utiliza para "pnner de relieve el hecho de que las políticas seguidas por estos Estados son diseñadas la mayoría de las veces para proteger grupos de interés a un costo neto para la sociedad y el Estado como un todo". Ve.ase Hansesn, Roger, ob., cit., p. 136. 
peligroso para la vigencia del sistema económico internacional diseñado en Bretton Woods.

Como bien dice Hansen, a pesar de que el camino neomercantilista aparece como el más perjudicial para el Sur, la dirección opuesta, es decir la implementación de nuevas estrategias multilaterales de cooperación intranorte, no implica necesariamente, que vayan a adoptarse actitudes más consideradas hacia el Sur. En el fondo; uno'u otro rumbo, desde la perspectiva del mundo en desarrollo, pueden ser irrelevantes. respecto a una mayor preocupación del mundo industrializado por la temática Norte-Sur ${ }^{23}$.

Interesa destacar aquí que de cualquier manera, la existencia de problemas económicos intranorte, que afectan su cohesión, contribuye a reforzar el estancamiento del diálogo Norte-Sur. Esto último es muy importante si se tiene en cuenta además que hay un aspecto, asimétrico en relación con el tema de la solidaridad del Norte en oposición a la solidaridad del Sur. La división de las naciones del Tercer Mundo, objetivo perseguido por muchos políticos del Norte, concede mayores márgenes de maniobra a los países desarrollados. Inversamente, la falta de cohesión del Norte, dificilmente mejore el poder de negociación del Sur frente al mundo industrializado (a excepción de las posibilidades bilaterales que podrían ofrecerse en este contexto a los países de la clase media internacional en àlgunos asuntos específico ${ }^{2 \dot{4}}$.

Cualquiera sea finalmente el camino que se siga, es observable que los cambios básicos acaecidos en los países industrializados en las disposiciones culturales. (debilitamiento de la ética protestante, expectativas de mejoras progresivas en los niveles de ingreso y empleo independiente de los aumentos reales en la producción y la productividad), las preferencias sociales y las estructuras políticas ("debilidad e ingobernabilidad" de las democracias, aumento de la participación real de amplios sectores anteriormente desplazados - minorías étnicas y religiosas- mujeres, jóvenes - que cuentan con medios para ejercer sus derechos e influir sobre los gobiernos- generan reacciones nacionales contrarias a los impactos externos y tienden a favorecer políticas orientadas "hacia adentro" del sistema".

De este modo, sus poblaciones, que aprendieron a gozar rápidamente de los beneficios que ofrece el "wellfare state", llevan sobre el sistema político a través de sus grupos de interés, una serie cada vez mayor de demandas, exigiendo acciones públicas para que se adopten micropolí-

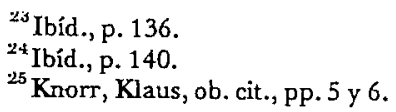


ticas de ajuste a fin de reducir o eliminar los efectos de los impactos económicos adversos (ejemplo: reducir la importación de zapatos, de textiles, de aceros especiales, etc.).

De mantenerse estas tendencias, podemos concluir con Knorr que: el futuro sistema será menos abierto que su predecesor. El movimiento de bienes y capitales será menos libre y el juego de las reglas del mercado estará sujeto a un mayor control gubernamental. El nuevo orden será más y no menos estado-céntrico. Como consecuencia de ellos el sistema estará más politizado que antes, especialmente en el sentido que los gobiernos estarán más involúcrados en el modelamiento de las transacciones que previamente estuvieron en manos de las empresas privadas. El orden que se está desarrollando será menos estable debido a las cambiantes preocupaciones gubernamentales, y la influencia para modelarlo estará más fragmentada internacionalmente que hasta ahora...

Las conșideraciones que los gobiernos tendrán que tener en cuenta para adoptar decisiones estarán gobernadas menos por la eficiencia y las ganancias que pueden derivarse del libre movimiento de bienes y capitales, y más por otras cuestiones relacionadas con el bienestar nacional al cual los pueblos son muy sensitivos, y más por sus propias preocupaciones sobre la seguridad económica nacional y por las vulnerabilidades económicas que comprometen esa seguridad ${ }^{226}$.

Frente a esta perspectiva, las posibilidades de adopción de mecanismos cooperativos intrabloques que conduzcan a reformas y mejoras sustantivas del sistema vigente, no son muy alentadoras, y el destino de la mayoría de los países del Sur en este nuevo orden no aparece muy halagüeño.

A pesar de la razonabilidad de los planteos de quienes defienden en el Norte la teoría de los intereses mutuos, las fuerzas que priman en la actual coyuntura siguen otorgando a la problemática del mundo en desarrollo un rol totalmente periférico ${ }^{27}$.

\section{Agravamiento de la Tensión Este-Oeste}

Existe en la actualidad en Estados Unidos y en-la mayoría de los países capitalistas, una percepción generalizada acerca de la pérdida creciente de terreno de Occidente frente al avance sistemático y planeado de la Unión Soviética.

${ }^{26}$ Ibíd., p. 12.

${ }^{27}$ Un buen trabajo en favor de la "teoria de los intereses mutuos" puede verse en Sewell, John W., Can the North Prosper Without Growth and Progress in the South, en The United States and World Development: Agenda 1979, ob. cit. 
Escapa al propósito de este trabajo indagar si esta apreciación es correcta o no. Sí importa a nuestros fines resaltar la influencia negativa que ejercen sobre el gobierno y la opinión pública vis a vis el conflicto Norte-Sur algunos acontecimientos que se desarrollan en la órbita del conflicto Este-Oeste.

Resulta evidente, a todas luces, que la naturaleza y modalidades del comportamiento del Norte respecto del conflicto Norte-Sur dependen en gran medida de la evolución de las relaciones entre las dos superpotencias. Dicho de otro modo, a mayor agravamiento de la tensión capitalismocomunismo internacional, menor preocupación por el tema Norte-Sur.

En el juego de poder Este-Oeste, la administración demócrata consideró que la mayor fortaleza de Estados Unidos residía en su poderío económico, en su capacidad de innovación y en la atracción que el sistema social, para algunos, o el modelo, para otros, norteamericano, ofrecía al resto de las sociedades del mundo. En este sentido, la Unión Soviética no era considerada, ni siquiera, una amenaza. Su poderío económico y capacidad de innovación estaban muy lejos de los niveles norteamericanos y se estimaba que su modelo societal burocrático colectivista, altamente represivo, era un producto que muy poca gente estaba ya dispuesto a importar.

Como es obvio suponer, acontecimientos como la intervención cubana en Angola y las crisis de Irán y Afganistán, manifestación clara de la lucha por el poder entre estados en términos ortodoxos, produjeron un rebrote del espíritu de guerra fría en amplios sectores de la sociedad norteamericana, que contaron con argumentos firmes para criticar, con las cartas sobre la mesa, los fundamentos mismos de la política de intereses globales de la Administración Carter.

Uno de los más lúcidos representantes de la corriente conservadora del Norte, Robert Tucker, en su artículo ya citado, critica con mayores bríos que nunca, y no sin razón, las bases teóricas de la estrategia proclamada por el gobierno demócrata respecto del Sur, que se asentó en la percepción de la existencia de vinculaciones armónicas entre los países industrializados y los países en desarrollo, y que minimizó, en consecuencia, las posibilidades de conflicto entre ambos mundos. Según sus propias palabras, "al pretender aparentemente, exceptuar de las relaciones Norte-Sur el conflicto sobre riqueza, poder y status que ha sido endémico a las relaciones entre los estados en el pasado, la Administración Carter mostró un optimismo extraordinario",28.

Algunas páginas más adelante, desde la óptica del clásico juego de

${ }^{28}$ Tucker Robert, ob. cit., p. 465. 
poder entre las superpotencias, agrega, afinando la crítica: "...ciertamente, los pueblos de los países en desarrollo no se caracterizan más, por la pasividad que alguna vez exhibieron. Pero este cambio ha impulsado a las superpotencias a alterar sus métodos de competencia por el poder y la influencia en el Tercer Mundo y no a abandonar esa competencia",29

Estas apreciaciones lo llevan a concluir que los mayores problemas de la política exterior de Estados Unidos en la actualidad consisten en mejorar notablemente el equilibrio militar global con la Unión Soviética; asegurar el acceso de Occidente al petróleo del Golfo Pérsico (incluyendo medios militares si fuese necesario); y mejorar sustancialmente la posición monetaria internacional del país.

Aunque desde una perspectiva distinta, el profesor Hoffmann, también en un reciente artículo, afirma, en lo que respecta a política exterior, que nada habrá más importante y urgente para Estados Unidos que el forjamiento de una nueva relación con la Unión Soviética ${ }^{30}$. Por representar acabadamente la opinión actual de los sectores conservadores de Estados Unidos —cuya audiencia se ha incrementado de manera notable-, vale la pena citar para concluir con este punto el siguiente párrafo de Tucker con respecto a lo que debe ser la correcta posición de Estados Unidos frente al Tercer Mundo:

"En estas circunstancias tendremos que elegir las ocasiones para el empleo del poder, no solamente con sabiduría y moderación sino con más sabiduría y moderación que en el pasado. No existe ninguna razón para no ejercitar la moderación una vez que hayamos retomado una posición desde la cual sea nuevamente posible elegir; por lo menos no existe ninguna razón para no hacerlo si asumimos que nuestra seguridad y nuestro bienestar no dependen de la creación —o de la recreación- del orden en el vasto Tercer Mundo. Hay que admitir que aquella asunción no encuentra una aceptación general hoy día, ya sea entre aquellos que creen que debemos ajustarnos a los cambios que ocurren en el Tercer Mundo, o entre quienes creen que debemos moldear cualquier cambio que ocurra, con el empleo de nuestro poder militar si fuera necęsario. Tanto para los "ajustadores" como para los "moldeadores" la interdependencia presunta del mundo de hoy es la que no permite que veamos con indiferencia relativa la mayor parte del cambio que está teniendo lugar en Africa, Asia y América Latina.

$\mathrm{Si}$ fueran verdaderamente ciertas las suposiciones actuales comunes

\footnotetext{
${ }^{29}$ Ibid., p. 470.

${ }^{30}$ Hoffmann, Stanley, Muscle and Brains, en Foreign Policy, $N^{\circ} 37$, ;winter $1979-$ 80 , p. 11 y subs.
} 
acerca del tipo y del grado de interdependencia que hemos forjado con el mundo en desarrollo, entonces habrá que concluir que tenemos por delante un período muy difícil, ya que la imposición y el mantenimiento de nuestra visión del orden en el Tercer Mundo requeriría un esfuerzo moral y material que representaría una carga muy seria para nuestros recursos, y aun entonces sin ninguna promesa sólida de éxito. ¿Es necesario este esfuerzo? Aparte de la sola excepción señalada en todas estas páginas, ¿existen otros intereses lo suficientemente obligatorios para merecer un esfuerzo de tal magnitud y de un resultado positivo tan incierto?

Si el petróleo es, en efecțo, la gran excepción, nuestro destino no depende del cambio que está ocurriendo en el Tercer Mundo. Si el petróleo es la gran excepción, podemos acomodarnos de otro modo a un Tercer Mundo que permanecerá bastante inestable por un período indefinido. Aún más, podemos mantenernos relativamente indiferentes a la mayor parte del cambio que está ocurriendo en los países en desarrollo. Esta indiferencia expresa, a su vez, una indiferencia hacia la perspectiva de que gran parte dèl mundo en desarrollo puede encontrarnos tan históricamente irrelevantes como nosotros los encontramos menos que vitales para nuestros intereses. Por cierto tien en muchas buenas razones para hacer$10^{231}$.

Modalidades internas del funcionamiento del sistema político norteamericano

Puede observarse también en Estados Unidos una crítica generalizada a las incoherencias e inconsistencias de la política exterior.

Se dice a menudo que el acento puesto en demasiadas metas, que fueron más bien un "catálogo de objetivos que una estrategia"332, produjo grandes fragmentaciones.

Si bien es cierto que la política exterior de Carter no se ha caracterizado precisamente por su coherencia, es preciso tener en cuenta las serias limitaciones que al manejo de esa política imponen las características estructurales del propio sistema global norteamericano y las modalidades actuales del funcionamiento del sistema político. En un mundo profundamente convulsionado por serias crisis políticas, sociales y económicas, el Estado norteamericano aparece como una estructura débil en relación con su sociedad civil.

Esta característica de "low stateness", del sistema político

${ }^{31}$ Tucker Robert, ob. cit., pp. 478 y 480.

${ }^{32}$ Hoffmann, Stanley, The Hell of Good Intentions, en Foreign Policy, $\mathrm{N}^{\circ} 29$, Winter 1977-8, p. 11.

${ }^{33}$ Sobre la debilidad del Estado norteamericano véase Katznelson Ira y Prewitt, 
- debida según Huntington a lo que él denomina sus tres rasgos inherentes: credo liberal, separación de poderes y pluralismo sociopolítico-, somete al gobierno a permanentes presiones, muchas veces inmanejables, de distintos grupos de interés ${ }^{34}$.

A esta debilidad estructural del Estado, debe agregarse el nuevo rol del Congreso que contribuye a aumentar el proceso de fragmentación de la política exterior iniciado en $1975^{35}$.

A partir de entonces los problemas económicos y politicos internos e internacionales han impuesto, por una parte, estrechos márgenes a las posibilidades del gobierno de restablecer una "meta nacional legítima" que sea capaz de nuclear a la opinión pública en favor de una detęrminada política exterior.

Contrariamente, la pluralidad de metas fijadas por la Administración Carter y la falta de una estrategia sólida, contribuyeron a aumentar las dificultades para reestructurar un consenso nacional respecto del accionar externo del gobierno.

Durante la etapa del "consenso" (1945-1975) la bandera de la seguridad nacional y la contención del comunismo internacional combinaron perfectamente consideraciones de política y moral haciendo que el Congreso apoyara, sin mayores reticencias, al Ejecutivo. Como dice bien Huntington "...con el foco puesto en la seguridad nacional, las políticas de la guerra fría tendían a estar separadas de las preocupaciones de los grupos de interés ${ }^{336}$. Inversamente y debido en buena medida a la guerra de Vietnam, en 1965 Estados Unidos entró en una etapa de polarización que se caracterizó por una casi permanente oposición del Congreso al Ejecutivo y por fuertes divergencias entre los imperativos de poder y moral.

Luego de la derrota de Vietnam la política exterior transitó a partir del año 1975, un período de fragmentación fuertemente marcado por la falta de convergencia respecto de los paradigmas.y como consecuencia de ello por la multiplicación de motivaciones nacionales válidas donde casi todo es "legítimo".

Este sistema fragmentado en el que no existe primacía de un poder sobre otro, una especie de "neither nor system" "37, está caracterizado

Kenneth, Constitutionalism, Class and the Limits of Choice in U.S., en Fagen Richard ed., Capitalism and the State in U.S. - Latin American Relations, Stanford, Stanford University Press, 1979.

${ }^{34}$ Ver Huntington, Samuel, ob. cit., pp. 4 a 11.

${ }^{35}$ Esta división de la política exterior de Estados Unidos en tres etapas - consenso, polarización y fragmentación- la hemos tomado de Huntington Samuel, ob. cit.

${ }^{36}$ Ibíd., p. 12.

${ }^{37}$ Ibid., p. 28. 
por una injerencia inédita del Congreso, en todas las áreas de la política exterior y por la ampliación de oportunidades para los grupos de interés de influir en el resultado del proceso legislativo.

En las palabras de Brzesinski el producto de esta evolución "fue no sólo un conflicto entre el Ejecutivo y el Legislativo sobre un número de asuntos de política exterior (ya sea Chipre o Panamá), sino también dado los amplios cambios en la sociedad norteamericana, una creciente intromisión en el debate político de asuntos más fragmentados. Con el anterior consenso ausente, 'con la élite WASP no más personalizando y legitimando un interés nacional giobal afirmado, los griegos pudieron hacer "lobby" más efectivamente y sin el temor de ser acusados de insensibilidad frente al interés nacional en el asunto Chipre; los judíos pudieron hacer lo mismo respecto del conflicto árabe-israelí, y más generalmente sobre la política norteamericana hacia el Medio Oriente o las Naciones Unidas; los sureños pudieron bloquear cambios en la política norteamericana respecto de Panamá y, derivativamente, hacia América Latina"38. Este sistema "neither nor" o "this and that" tiene una inmensa importancia para el tema Norte-Sur. Al obligar a un debate permanente sobre la mayoría de los temas relacionados con la política externa, permite que los grupos de interés puedan ejercer presiones sobre el Congreso, que en general ha sido proclive a apoyar sus demandas.

Ante la gravedad de los problemás económicos internos -inflación, desempleo, recesión- resulta comprensible que los legisladores apoyen políticas de corto plazo, de acuerdo con los intereses de esos grupos -que en general son desfavorables para el mundo en desarrollo y en el largo plazo para la sociedad global (como en el caso del proteccionismo respecto de los productos manufacturados de los países, semiindustrializados)— para evitar posibilidades de retaliación en el proceso electoral.

Otro punto importante que debe tenerse en cuenta son los cambios, en la opinión pública de los países del Norte, respecto de las prioridades de la política exterior debidos a las modificaciones del cuadro de situación internacional ya șeñaladas. Puede observarse que predominan los asuntos internos sobre los externos; una opinión generalizada que sostiene que el desarrollo es una cuestión puramente nacional; un gran escepticismo acerca de la eficacia de la ayuda externa (se discute mucho sobre el destino que las élites dirigentes del Sur dan a la misma) y una actitud crítica hacia las Naciones Unidas, especialmente hacia los países donde predominan las coaliciones del mundo en desarrollo.

\footnotetext{
${ }^{38}$ Brzezinski, Zibgniew, America in a Hostile World, in Foreign Policy, $\mathrm{N}^{\circ} 23$, Summer 1976, p. 86 .
} 
Si bien la opinión pública es altamente maleable, difícilmente se modifique en un tiempo corto su percepción acerca de los temas económicos que componen la agenda del NOEI, y será poco probable que alguno de sus planteos pueda convertirse en una bandera política capaz de movilizarla.

De acuerdo con Doone "...aunque los líderes políticos de las democracias industriales puedan contar con una cantidad modesta de sentimientos humanitarios para apoyar incrementadas transferencias de recursos a los países en desarrollo, los costos políticos de tan sólo mencionar el NOEI son demasiados altos, a menos que sus resultados ayuden a acallar las dislocaciones causadas por los acontecimientos económicos externos, 39 .

Problemas en el SUR

En nuestro trabajo anterior mencionamos las dificultades que encontraría el Sur para mantener la cohesión que lo caracterizó en los años 19741975. Existen varios aspectos que juegan crecientemente en contra de ello.

El elemento negativo clave en este sentido es, sin duda, la diferenciación en los niveles de desarrollo y potencialidades de los países del Sur, que los conduce a la adopción de posiciones no convergentes y al favorecimiento de estrategias distintas frente al mundo industrializado. Así, coexisten intrabloque una serie de diferencias sustanciales relacionadas con la naturaleza de la vinculación con el Norte, el orden de prioridades de las demandas que componen la agenda del NOEI, el modo de negociación con los países industrializados y el grado de afinidad con los sistemas de valores de las sociedades desarrolladas.

Varios países que conforman la denominada clase media internacional han alcanzado en los últimos años notables niveles de crecimiento, o, como en el caso de los países más importantes de la OPEP, acumulado enormes reservas financieras que los colocan en un plano marcadamente distinto del resto del mundo en desarrollo. Esto último es así percibido por estos propios países, como también por las naciones del Norte. Cuanto más se acrecienta la diferencia de niveles de desarrollo mayor es el alejamiento de las posiciones radicales y menores las posibilidades de comportamiento como bloque cohesionado, salvo en aquellos foros blandos donde prevalece la retórica sobre la realidad.

${ }^{39}$ Denoon, David B.H., ob. cit., p. 19. 
Si se tiene en cuenta, por otro lado, que estos países han logrado notables niveles de crecimiento dentro del sistema económico capitalista vigente, se comprenderá su escaso interés en modificarlo sustancialmente para que adquiera las formas deseadas por los países de menor desarrollo más radicalizados. Su voluntad de inserción privilegiada aunque subalterna en el Norte encaja perfectamente con la estrategia de cooptación desarrollada por los países industrializados en la actualidad y tiene además un fundamental correlato interno. La mayoría de los países que componen esta clase media internacional están gobernados por gobiernos de tipo autoritario o por democracias formales que controlan, a través de diveros mecanismos, la movilización y participación de los.sectores populares.

El modelo opuesto a la cooptación, la "self reliance", resulta poco atractivo para los sectores dominantes. En su dimensión interna la puesta en práctica de este modelo exigiría una alta movilización de la población y un aumento de la conciencia política de todos los sectores a través de una creciente participación en el proceso político y productivo. Dadas las características actuales de estos sistemas políticos es comprensible la aversión de las élites dirigentes por este modelo de la "self reliance", ya que éste implica sustanciales modificaciones en la estructura de clases de cada país y en la distribución del ingreso.

Estas políticas conducentes a la "salvación individual", que dejan flotando en el aire un trágico interrogante acerca del destino de los países más pobres, conllevan generalmente a la adopción de políticas regionales, proclives a la formación de esferas de influencia que atentan contra los esquemas de integración autonomizante.

Para mencionar tan sólo un ejemplo, es interesante observar el sentimiento creciente de muchos países del Caribe contra el expansionismo venezolano-mexicano. En 1975 Erik Williams, primer ministro de Trinidad y Tabago, proporcionó una muestra de estos sentimientos cuando declaró que "el Caribe está siendo colonizado de nuevo esta vez, por Venezuela" ". La vieja historia de la humanidad parece repetirse.

Otro elemento fundamental que contribuye a la diferenciación del bloque Sur es la discusión en torno al orden de prioridades de las demandas que componen la agenda del nuevo orden económico internacional.

Su plataforma contiene una amplia serie de proposiciones que enfatizan soluciones de tipo global, tales como el programa integrado de productos básicos y en fondo común, mecanismos mundiales y automáticos para

${ }^{40}$ Citado por Treverton, Gregory T., El interés económico y la ambición política en las relaciones externas de América Latina: Brasil, México y Venezuela, en Cuadernos Semestrales del Cide, $N^{\circ} 5,1^{\text {er }}$ Semestre, 1979, p. 170. 
la transferencia de recursos financieros, el sistema general de preferencias, etc.

Conforman una serie de reclamo generales sin un orden de prioridad.

Sin embargo, más allá de estos planteos, se dan en la realidad, dadas las diferencias de desarrollo existentes en el Tercer Mundo, prioridades e intereses específicos, no siempre coincidentes, $y$ en algunos casos con firme tendencia a hacerse contradictorios. Ejemplos en este sentido pueden encontrarse en la actitud prescindente de los países más industrializados - tal el caso de Brasil, Argentina y México- frente al tema de la deuda pública o la posición moderada de los países con enormes disponibilidades financieras frente al tema de las reformas al orden monetario internacional vigente. Las prioridades específicas bifurcan los caminos, los acentos se colocan en sílabas distintas y los países emergentes tienden a transitar rumbos menos azarosos buscando soluciones concretas y aparentemente más cercanas, como el accéso de sus productos manufacturados a los mercados del Norte y a las fuentes internacionales de capital privado, el logro de nuevas formas de contratación para el capital extranjero y las empresas transnacionales, un mayor control sobre el proceso de transferencia de tecnología, y una participación adecuada a su creciente importancia en el proceso de redistribución industrial a escala mundial ${ }^{41}$.

Otra de las causas que han contribuido al estancamiento de las negociaciones ha sido el favorecimiento, por parte de los países más radicales, de posiciones "maximalistas". Las exigencias globales fueron tan grandes que impidieron o imposibilitaron cualquier tipo de negociación parcial. Este tipo de planteos de "prioridades excluyentes", como bien lo definiera Roger Hansen, contribuye a la diferenciación intrasur, ya que los países mayores son partidarios de una menor rigidez en las negociaciones: $y$ en general favorecen posiciones de tipo "incrementalista". En este sentido, puede observarse de parte de estos países una actitud cautelosa y especuladora en el seno de las estructuras internacionales que agrupan a los países en desarrollo como la UNTACD, y el Movimiento de Países no Alineados.

Un cuarto aspecto que juega claramente en favor de las diferencias, y esto es especialmente significativo para los países mayores de América Latina, es la "comunidad de valores existentes entre las naciones del Norte y algunas semiindustrializadas respecto de las ideas, creencias

\footnotetext{
${ }^{41} \mathrm{Ver}$ informe de Progreso sobre el Estudio sobre América Latina y el Nuevo Orden Económico Internacional, Programa de Estudios Conjuntos sobre las Relaciones Internacionales de América Latina (RIAL), Boletín Informativo $N^{\circ} 3$, Buenos Aires, noyiembre 1978 , pp. 3 y 4.
} 
y símbolos que conforman el sistema de valores del mundo occidental. Desde este punto de vista, resulta obvia la mayor afinidad de América Latina con el mundo europeo y norteamericano que con los países de Asia y Africa, con los qúe, salvo algunas excepciones, no existen vínculos pasados ni presentes de mayor relevancia.

Finalmente antes de concluir este punto, nos interesa resaltar que si el proceso de diferenciación del Sur, indudablemente inevitable, continúa marchando en las direcciones presentes, conferirá al Norte crecientes márgenes de maniobra frente a las demandas del nuevo orden económico internacional. Esta sería la contrapartida norteña del proceso de proliferación del poder político y económico mundial que otorga a algunos países del Sur una permisibilidad de movimiento internacional autónomo desconocida hasta el presente.

\section{ESTANCAMIENTO Y COOPTACIÓN:}

\section{TÁCTICA Y ESTRATEGIA DEL MUNDO INDUSTRIALIZA DO}

Una primera observación superficial de la actitud del Norte ante el NOEI, sugiere que los temas de los diálogos del Norte-Sur han perdido relevancia frente a otros asuntos más prioritarios que debieron enfrentar los países industrializados en los últimos años. Sin embargo, lo que efectivamente ha sucedido no es que los asuntos incluidos en el NOEI hayan disminuido en importancia para el Norte, sino que los reales paradigmas se han hecho más explícitos debido a las dificultades que ofrece la coyuntura internacional.

Puede apreciarse en general, que tanto desde la perspectiva económica como de la seguridad nacional, los aspectos relacionados con la problemática Norte-Sur continúan siendo de limitada importancia para las naciones desarrolladas.

En conversaciones recientes que mantuvimos con diversos representantes de los sectores políticos y económicos de los países industrializados, hemos podido apreciar un rechazo total a negociar la mayor parte de las demandas globales contenidas en el NOEI. La táctica es producir su estancamiento.

Esta actitud "low profile" se explica esencialmente por dos razones. En primer término, por la continuidad de la vigencia en el Norte de dos paradigmas básicos de las relaciones económicas internacionales presentes -que el interés nacional puede alcanzarse sin desarrolar una gran capacidad de interacción sobre bases constructivas con el Sur y la creencia indiscutida de que el sistema económico internacional vigente es suficientemente capaz para resolver los problemas que 
aquejan a los países en desarrollo- ${ }^{42}$, y en segundo lugar por la rápida pérdida de peso relativo de las economías del Tercer Mundo en las transacciones económicas internacionales.

En efecto, "los países de Asia, Africa y América Latina generaban, a fines de la década de 1940 , el $30 \%$ de las exportaciones mundiales y a principio de la de 1970 sólo el 17\%. La débil participación de la región en el comercio mundial y su significación contemporánea y en el proceso de industrialización debía necesariamente, apartarlos de las corrientes más dinámicas de la economía internacional. Con excepción del petróleo, los países atrasados perdieron importancia relativa dentro de los intereses básicos de las economías industriales" ${ }^{\prime 43}$.

En consecuencia, entre las diversas posiciones del Norte respecto de la mejor relación con el mundo en desarrollo, la que prevalece en la actualidad es la que pretende generar un sistema de alianzas selectivas con los países que forman la denominada clase media internacional, y al mismo tiempo, fragmentar la unidad del Sur más que aceptar y negociar con los países en desarrollo como un bloque legítimo en las relaciones internacionales. Esta estrategia mayoritaria basada en incorporaciones unilaterales al "club de los ricos" y fuera del esquema Norte-Sur, constituye aparentemente el grado de respuesta máxima que los séctores dominantes de los países desarrollados están dispuestos a ofrecer al Tercer Mundo.

Los criterios que se toman en cuenta para identificar a los "cooptables". son: estructura industrial importante (Brasil, México, Argentina y Venezuela); abundancia de recursos naturales (Nigeria); poder nuclear real o potencial con significativo potencial militar regional (India, Brasil, Argentina); e importancia financiera emergente (Arabia Saudita). La característica común de todos estos países es su "capacidad de interferir en el logro de las metas de la política interna e internacional de los países del Norte" ${ }^{\text {,44 }}$.

Siguiendo a Hansen podríamos decir que los tres puntos principales que caracteriza la estrategia "bring them into the system" son: a) integración de los países mayores en el sistema internacional, a través de un juego de concesiones recíprocas. Se espera que los nuevos socios acepten y apoyen las normas del mundo desarrollado; b) aceptación de algunos cambios incrementalistas que respondan a las necesidades de los países no cooptables (se apoya en general las negociaciones para

\footnotetext{
${ }^{42}$ Ver Hansen, Roger, Can The North-South Impasse be Overcome, Washington, Overseas Development Council, 1979, Development Paper $\mathrm{N}^{\circ}$ 27, pp. 23 y 24.

${ }^{43}$ Aldo Ferrer, ob, cit., p. 30.

${ }^{44}$.. Hansen Roger, Beyond The Nort-South Stalemate, ob. cit., p. 174.
} 
el desarrollo, el fortalecimiento de instituciones para asistir a los países del Sur tales como el Fondo Monetario Internacional y el Banco Mundial), y c) mantenimiento del sistema vigente acompanado de la creencia de que "los cambios incrementalistas en número limitado de campos son suficientes para aliviar las tensiones Norte-Sur y administrar los problemas que el sistema internacional de la década del 80 probablemente enfrentará" ${ }^{45}$.

Esta estrategia de cooptación tiene dos objetivos, uno a corto y otro a largo plazo. El primero de ellos es la incorporación de los países de la clase media internacional al sistema vigente. El segundo consiste en la integración de todos los países que componen el Tercer Mundo a través de un proceso gradual y mediante la adopción progresiva de reformas institucionales y económicas que respeten las reglas del juego del sistema actual ${ }^{46}$.

En un trabajo publicado en 1979 por el Overseas Development Council John Mathieson, expresó, quizás con más claridad que nadie el futuro camino que deberá seguir el Norte para lograr los dos objetivos enunciados: "Lo que se necesita es un nuevo mecanismo en el cual los países en desarrollo avanzado y los países industrializados puedan analizar y formular estrategias sobre bases cooperativas multilaterales con el objetivo último de integrar a los países de desarrollo avanzado como socios plenos de la economía internacional...

Mientras que una estrategia para cooptar a los países en desarrollo avanzados a expensas de otros países en desarrollo esteóricamente posible, sería mucho menos viable políticamente que una estrategia que recibiera el apoyo del Tercer Mundo en su totalidad. Esto implica que la adopción de acciones conjuntas sería beneficiosa (o al menos no perjudicial) para los países menos avanzados. Las iniciativas deberían apuntar a expander las posibilidades de este tipo de naciones de acceder a los mercados y a los recursos técnicos y financieros disponibles" ${ }^{\prime 47}$.

Resulta de interés destacar aquí, que esta apertura del Norte hacia algunos países mayores del Tercer Mundo no es casual. La misma debe explicarse a la luz de los acontecimientos que han modificado algunas de las reglas de juego del sistema internacional.

El proceso de proliferación del poder requiere, justamente, el desarro-

${ }^{45}$ Ibíd., p. 179.

${ }^{46}$ Ibíd., p. 177.

${ }^{47}$ Mathieson, John A., The Aduanced Developing Countries: Emerging Actors in the World Economy, Washington, Overseas Development Council, 1979, Development Paper $N^{\circ} 28$, pp. 55 y 58. 
llo de estrategias cooptacionistas respecto de los posibles desafiantes al Norte, para evitar al mismo tiempo que se pretenda asumir en algún caso el eventual liderazgo del "proletariado de naciones" en aras de una revolución política y social universal. En otras palabras, las actuales condiciones del sistema internacional, una de cuyas características relevantes es la limitación al uso de la fuerza militar, imponen la apertura de algunas vías de acceso al sistema a los que aparecen como poderes emergentes. En palabras de Hoffmann "la influencia, más que el control está en el corazón del proceso. Existen muchos factores como para que uno de ellos (países industrializados) pueda ejercer una importancia decisiva en todos los frentes o por un período prolongado, especialmente cuando el uso de la fuerza está limitado"48.

Debe tenerse en cuenta sin embargo que ante las dificultades para "controlar", las capacidades de "influir" se ven seriamente disminuidas. La cooptación, como el uso del poder militar, también ehcưentra sus límites.

Desde el punto de vista de la seguridad por ejemplo, el requisito sine qua non que habilita a incorporarse al sistema, es la afiliación de los nuevos socios al sistema de valores de occidente. Pero si de este requisito básico, cuya aceptación en general no presenta inconvenientes, pasamos a los intereses nacionales particulares de los paísẹs cooptables la afinidad de valores y criterios pierde nitidez, tal el caso de los temas relacionados con la proliferación nuclear, los derechos humanos, las formas de gobierno, etc. Aquí se introducen grandes dificultades en relación con las reglas de juego de las concesiones recíprocas que caracteriza a todo proceso cooptacionista. Esta observación es válida también desde la perspectiva económica. La mayor permisibilidad internacional existente favorece, en muchos casos, la adopción de conductas heterodoxas y "neomercantilistas" por parte de los países de clase media que conllevan un potencial de conflicto con el Norte (por ejemplo la venta de trigo de la Argentina a la Unión Soviética luego de la invasión rusa a Afganistán, a pesar de las fuertes presiones que recibió de los Estados Unidos en sentido contrario).

Por otra parte, el proceso de cooptación, frente a la primacía de los factores políticos internos sobre los externos, tropieza asimismo con crecientes dificultades. De acuerdo con Ferrer "parece bastante claro que la intervención en los asuntos internos del Tercer Mundo sólo es posible si se dan ciertas condiciones geopolíticas y en países de dimensión suficientemente reducida. En estos casos, como en algunas experiencias

\footnotetext{
${ }^{48}$ Hoffmann, Stanley, Primacy or World Order, ob. cit., p. 114.
} 
recientes en Africa la intervención foránea puede tener peso relativo suficiente como para influir en la marcha de los acontecimientos. Pero en los países de mayor dimensión la intervención debe limitarse a promover la "desestabilización" de los gobiernos hostiles o dar apoyo económico y político limitado a los amigos. En los países del Tercer Mundo de dimensión apreciable los conflictos políticos expresan predominantemente las tensiones internas de las sociedades nacionales. En tales casos, las posibilidades de intervención foránea son limitadas y, como lo revela la experiencia frecuentemente, sus resultados contradicen los objetivos perseguidos. Esto no excluye que los alineamientos políticos internos busquen insertarse en alguno de los campos en pugna dentro del orden internacional. Pero nuevamente las opciones internas suelen ser más decisivas en estos casos que la intervención foránea. Las experiencias registradas en América Latina y en otras regiones, como la muy reciente en Irán, insinúan este carácter dominante de los factores internos en la evolución política de los países del Tercer Mundo"49 .

Dada justamente la importancia de estos factores internos, por los límites que imponen a la estrategia de cooptación, dedicaremos la última parte de este trabajo a desarrollar algunas reflexiones en torno de las tendencias políticas observables en los países mayores de América Latina, región que, naturalmente, concentra nuestra preocupación e interés.

\section{Tendencias políticas observables en America Latina}

En el contexto internacional descripto y dados los particulares problemas que supone la transición hacia un orden internacional (tanto político como económico) sensiblemente distinto al que ha predominado en las últimas décadas, es interesante concentrar la atención en los posibles cursos de acción de algunos países latinoamericanos que tienden a lograr una inserción más ventajosa y adecuada a las actuales reglas de juego del sistema.

Para acotar el análisis centraremos nuestra atención en los países mayores del área que reclaman para sí una categoría de clase media internacional, y cuyo peso relativo en términos económicos y estratégicos hace previsible un tratamiento diferenciado por parte de los países del Norte, al mismo tiempo que alienta una vocación de "potencia emergente" en cada uno de ellos.

Como hemos mencionado en nuestro trabajo anterior, ya citado, pue-

\footnotetext{
${ }^{49}$ Ferrer, Aldo, ob. cit., pp. 43 y 44.
} 
de observarse de parte de las élites dirigentes de estos países - al margen de la diversidad de sus'regímenes políticos- un esfuerzo de reacomodamiento en el espacio ampliado del sistema económico mundial que los acerque al mundo industrializado capitalista, convirtiéndolos en socios plenos, aunque subordinados, con un rol establemente definido en la estrategia global de los países desarrollados.

Se entiende entonces que'su posición frente al problema de la reformulación del orden económico internacional vigente esté a una distancia más que considerable de la de aquellos países nítidamente no industrializados que se asumen a sí mismos como del Tercer Mundo, y que sólo advierten posibilidades reales de desarrollo si se producen cambios estructurales en el sistema económico mundial.

La ambigüedad en la definición de la postura de los países mayores de América Latina tiene un sentido más bien político que económico. Se agranda por su incómoda ubicación en la franja nebulosa que separa al mundo semiindustrializado de los países más desarrollados, y se alimenta de la necesidad de no cortar amarras con el Sur al que en verdad. pertenece, pero no encubre la indiferencia con que encara los temas vitales del Nọi y la falta de compromisos con programas de cambios sustantivos.

Es por eso mucho más cercana a la "estrategia de estancamiento" del Norte a la que antes aludíamos.

A la luz de este objetivo básico deben analizarse los cambios observables en los sistemas políticos y económicos de los países mayores de la región, que forman parte de un nuevo orden visualizado como un instrumento para "racionalizar el mundo de la escasez" o para "mundializar un equilibrio económico" a partir de las economías centrales, sustituyendo el concepto de desarrollo por el de "normalización" según la descripción de Cándido Méndes ${ }^{50}$.

Los interrogantes mayores que cabe plantearse al respecto se relacionan con los siguientes temas:

1. Las pautas básicas de las políticas económicas implementadas por los gobiernos de los países mayores - tanto democráticos como autoritarios. La afinidad o contraste con el orden internacional tal como es visto por los países desarrollados.

2. La compatibilidad o incompatibilidad del modelo de desarrollo resultante con las aspiraciones de la sociedad en cada uno de esos países, y la capacidad potencial de las fuerzas sociales nacionales para influir

\footnotetext{
${ }^{50}$ Cándido Méndes, Jornal de Brasil, Suplemento Especial, 24-2-1980.
} 
sobre las élites dirigentes y eventualmente frustrar la consecución de sus objetivos.

3. Las reglas de juego político requeridas para asegurar la eficacia de las políticas económicas y la relación con los cambios orientados hacia formas diversas de autoritarismo.

4. El Estado como agente principal de cambio y las tensiones a mediano plazo entre el Estado "liberal" y "subsidiario" y las exigencias derivadas del proceso de industrialización, de la debilidad crónica del empresariado nacional y de la marginalidad política y/o económica de los sectores populares.

5. La viabilidad de formas de democracia limitada. Las "amenazas" originadas en las fuerzas sociales desplazadas pero subsistentes. La ausencia de alternativas reales para canalizar las demandas de los sectores representados por los movimientos "populistas". La estabilidad del sistema político elevada a la categoría de primer objetivo.

6. La actitud y organización del movimiento obrero como variable fundamental para el análisis del éxito o el fracaso del modelo propuesto por los grupos dirigentes.

7. Las alternativas ficticias. Las propuestas socialdemócratas. El agotamiento del populismo. La revalorización de los partidos de centro. La convergencia cívico-militar o la participación institucionalizada de las Fuerzas Armadas en el sistema político.

Varios de estos temas están siendo extensa y calificadamente estudiados por numerosos cientistas políticos. Nuestro objetivo es señalar algunos aspectos de la interacción de factores políticos, sociales y económicos que pondrían en evidencia que el proyecto de sistema político y de inserción internacional, que están tratando de implementar las élites dirigentes de los países mayores de América Latina, no ha tomado debida cuenta de elementos esenciales relativos al grado de movilización política de la sociedad, desarrollo y organización del movimiento obrero, necesidad vital de consenso para consolidar el sistema, y previsibles cursos de acción de otros grupos no alcanzados por los beneficios del modelo, como por ejemplo el empresariado nacional.

$\mathrm{Al}$ ofrecer alternativas para el mediano plazo que no incluyen realmente a los sectores ahora desplazados y controlados, es previsible que éstos buscarán recuperar la participación perdida, pasando de la apatía a la contraofensiva, a través de nuevas o viejas formas.

El agotamiento del populismo como alternativa política parece, así, mucho más una expresión de deseos de los grupos dirigentes que un dato de la realidad, al menos en el Cono Sur de América Latina; la estabilidad del sistema y la democracia "orgánica y moderna" una meta lejana a la que se está tratando de llegar por caminos erróneos. 
En aquellos países más industrializados de América Latina, en que los regímenes autoritarios del presente sucedieron a gobiernos de tendencias populistas o izquierdistas, la reformulación global de la política económica parece ser el objetivo prioritario. Como son justamente estos países los que estamos analizando y en especial los del Cono Sur; es útil reiterar algunos conceptos conocidos, respecto. de las políticas económicas que han sido puestas en práctica y del rol internacional que estos países se autoasignan. El principio rector es, en todos los casos, la "apertura económica" que se supone les permitirá convertirse en países modernos, integrados al mundo y con peso en el concierto internacional ${ }^{51}$.

La gravedad de las crisis económicas sufridas en el período anterior, con su secuela de inflación, desorganización del àparató productivo, alta movilización del sector laboral, pérdida de crédito externo y angustiosa escasez de reservas, les ha dado la posibilidad de asumir un control más sólido del Estado y contar con un mayor margen de tiempo para ejecutar una política que se pretende produzca algunas modificaciones irreversibles en el sistema económico naciona ${ }^{5}{ }^{52}$.

La apertura y el retorno a la ortodoxia se dan en un contexto internacional en el que ya no tienen vigencia los ideales de crecimiento continuo, difusión de la prosperidad, liberalización de las economías y estabilidad de precios, propio de la década del sesenta.

Los instrumentos para "sanear" y "reorganizar la economía", recuperar la "respetabilidad" internacional, controlar la inflación; equilibrar la balanza de pagos y reponer las reservas internacionales, son utilizados en su versión más ortodoxa (Chile) o con algunas concesiones pragmáticas a la peculiar coyuntura internacional (Brasil); no queda oculto sin embargo el hecho de que existen contradicciones, tanto entre la teoría económica que se sostiene y su ejecución práctica, como entre el modelo que se dice defender y el que previsiblemente resultaría de la aplicación pura y simple de esas políticas. En cuanto a lo primero, el ejemplo más evidente parece ser el referido al rol del Estado en esta etapa del desarrollo de los países mayores, toda vez que mientras el sector público, la burocracia estatal y las propias empresas estatales crecen y se fortalecen mucho más allá de lo previsible la filosofía liberal vigente

\footnotetext{
${ }^{51}$ Según las palabras del Secretario de Comercio Exterior y Negociaciones Económicas Internacionales de Argentina, Lic. Alejandro Estrada (v. Clarín, 18-3-80, p. 11).

${ }^{52}$ Sobre este punto of. Guillermo O'Donnell "Tensiones en el Estado BurocráticoAutoritario y la cuestión de la democracia", Documento cedes G.E. clacso, $N^{\circ} 11$. Buenos Aires, 1978, pp. 19-26, Alfred Stepan, "The State and Society. Peru in comparative Perspective", Princeton, Princeton University Press, 1978, (cap. $3^{\circ}$ pp. 73 y siguientes).
} 
no cesa de acentuar los males derivados del gigantismo estatal y la necesidad de volver al Estado su rol subsidiario natural ${ }^{53}$.

La segunda contradicción señalada nos lleva al análisis de los reales objetivos de las políticas ortodoxas predominantes.

En énfasis en el valor eficiencia, dada la actual relación de fuerzas entre el mundo industrializado y el subdesarrollado significa poner en marcha un proceso de concentración industrial que margina la pequeña y mediana industria nacional. Ello se vio claramente en el caso de Brasil, sobre todo en la etapa del gobierno autoritario iniciada en 1971, y es la línea adoptada por la Argentina a partir de 1976.

No se trata, entonces de implementar una política que conduzca a una mayor integración industrial, sino que se racionaliza una nueva división internacional del trabajo. Cabe preguntarse si el sector industrial nacional, ya bastante organizado y complejo, podrá ser tan resueltamente marginado del poder económico y político cuando se liberalicen los respectivo regímenes políticos o si, por el contrario, se convertirá en un generador de tensiones para el régimen capaz de alterar el curso de los acontecimientos ${ }^{54}$.

Hay un correlato cierto entre el modelo económico prevaleciente entre los países mayores, por un lado, y las características de los regímenes políticos que los implementan, por otro. Las exigencias derivadas del modelo económico condicionan la marcha del proceso político y reducen las alternativas disponibles. Máxime, si lo que se procura consolidar es, en general, un tipo de desarrollo liberal, ortodoxo, excluyente de vastos grupos sociales y muy afín a lo que podría considerarse la estrategia de los países industrializados.

Este tipo de desarrollo ha sido, quiérase o no, el blanco preferido de las críticas consistentes provenientes de variados sectores (populistas, desarrollistas, de izquierda) en los últimos veinte o veinticinco años, es decir, en el importante período de formación de una conciencia política de masas que generó modificaciones fundamentales en el sistema político. A cambio de ese modelo de desarrollo que reduce la participación en la riqueza nacional y en la toma de decisiones políticas, de grupos mayoritarios en cada país, ya no se puede ofrecer la panacea del creci-

\footnotetext{
${ }^{53}$ Para el estudio de este tema son importantes los trabajos de Guillermo O'Donnell, "Reflexiones sobre las tendencias generales de cambio en el Estado Burocrático-Autoritario", Documento cedes/G.E. Clacso $\mathrm{N}^{\circ}$ 1; Albert O. Hirschman, "The Turn to Authoritarianism in Latin America and the search for its economic determinants" en "The New Authoritarianism in Latin America", ed. by David Collier, Princeton, Princeton University Press, 1979, (cap. 3, pp. 61-98).

${ }^{54}$ Una síntesis de las críticas del sector industrial argentino al programa económico pueden verse en el documento de las entidades representativas del empresariado indus= trial (MEDI, MIA, UIA) (v. Clarín, 19-10-79).
} 
miento vertiginoso, limitando así lo que Hirschman llama "tolerancia a la desigualdad", que es mayor cuanto mayor es la rapidez del crecimiento $^{55}$.

La reducción de alternativas, a la que hacíamos referencia, surge, en principio, porque difícilmente regímenes realmente abiertos, pluralistas $y$ democráticos, funcionando en sociedades con un grado significativo de organización y politización, pueden sostener políticas económicas que marginan a sectores mayoritarios y desplacen, hacia abajo, a grupos económicos nacionales, modernos y ya sólidamente insertados en el sistema económico y político, luego de los cambios operados. a partir de la década del 40 . No se trata de que el giro hacia sistemas políticos más restrictivos, en cuanto nivel de participación, tenga su causa exclusiva en factores de orden económico nacional e internacional. Sin perder de vista la importancia fundamental de éstos en la explicación del proceso. de limitación de la participación, no se pueden dejar, de lado los aspectos rèlacionados con la amenaza derivada de la polarización del sistema político observable en los países mayores de América Latina, desde fines de la década del 60 , utilizada para justificar el celo autoritario que, en mayor o menor grado, va penetrando en los sistemas políticos del área.

Partiendo de la base de que un desarrollo no capitalista no es considerado alternativa por quienes detentan el poder real y/o formal de los países que analizamos, ya quedan excluidos los grupos políticos de izquierda, radicales o no, de la posibilidad de lograr una participación plena e institucionalizada en el sistema y, mucho menos, de llegar al poder. En el momento actual, habida cuenta de las últimas experiencias de gobierno nacional-populares en el Cono Sur, de las crisis emergentes y de las nuevas condiciones económicas internacionales, la tendencia es producir mayores exclusiones. Ya no la de quienes cuestionan las bases mismas del sistema vigente, sino la de aquellos que reprèsentan una "vuelta al pasado", que se pretende irreversiblemente superar. Esta exclusión no es menor. Diríamos que es el punto definitorio del sistema. Además, no es asumida explícitamente y es relativamente nueva, por lo menos en su forma actual.

El objetivo de controlar los sectores populares e impedir su desarrollo autónomo no es nuevo, y menos nuevo resulta todavía, el de cercenar a sus partidos o movimientos representativos las oportunidades de llevar a la práctica sus programas; pero lo que sí parece más novedoso es el presente autoconvencimiento de las élites dirigentes de" que este modelo populis-

${ }^{55}$ Alberto Hirschman, ob. cit., p. 94. 
ta está agotado y que su retorno al poder debe ser evitado aún al precio de sacrificar el sistema político democrático en aras de la estabilidad y la seguridad. La exclusión de movimientos populares que hasta ahora representan a la mayoría de la población de sus países, no es explícita, porque ningún gobierno (en esta etapa del desarrollo político) desnuda tales intenciones. Pero aparece transparente, detrás de las manifestaciones y acciones oficiales, aún en los casos en que se está haciendo profesión de fe democrática.

En el caso de Brasil, en esta etapa aperturista inaugurada por Geisel e implementada por Figueredo, el panorama se hizo más claro al ponerse en marcha el proceso de reformulación partidaria.

Por un lado, porque a pesar de los largos quince años de ejercicio autoritario del poder - al abrirse los grifos de la liberación política, reaparecieron, aún vigorosos, los mismos viejos partidos de la etapa presuntamente precluida $^{56}$. Y en realidad, no h́ay ninguna razón para suponer que, en quince años, partidos políticos entroncados con la historia moderna del país, puedan diluirse mágicamente en las aguas de un autoritarismo excluyente.

Además, porque la congelación y el control exacerbado de la vida política, produce la apatía de la que habla O'Donnell ${ }^{57}$ pero es, en el mediano plazo un campo apropiado para la polarización de las fuerzas políticas y estéril para el surgimiento de las nuevas alternativas.

La experiencia argentina ratificó esto en 1973, cuando los votos obtenidos por el peronismo reflejaron, al mismo tiempo, la perdurabilidad de su vigencia - pese a los casi veinte años transcurridos- y la consolidaçión del sentimiento oposicionista en vastos sectores medios, no tradicionalmente peronistas, a los que el régimen militar no ofreció ninguna opción valedera.

Desde este punto de vista, la insistencia en erradicar los rasgos populistas dominantes en la sociedad, más obsesiva desde 1976, no parece destinada al éxito que sus formuladores esperan.

Conscientes de los datos clarísimos. que ofrece la historia reciente, los gobiernos que administran esta etapa se proponen ofrecer; desde arriba, alternativas "potables" para encauzar el sistema político por un camino menos azaroso.

Para ello tienen que manipular el sistema de partido de forma de neu-

\footnotetext{
${ }^{56}$ Cf. artículo de Acilio Lara Resende "Tudo que é demais nao existe" en Jornal do Brasil, 16-1-80, p. 11.

${ }^{57}$ Guillermo O'Donnell, “Tensiones...”, p. 13. Para una caracterización muy adecuada de los regímenes autoritarios y su relación con la sociedad civil, ver Fernando Henrique Cardoso, "On the Characterization of Authoritarian regimes in Latin America", en "The New Authoritarianism im Latin America", citado (cap. 2, pp. 33-57).
} 
tralizar cualquier oposición radical y crear la atmósfera apropiada para fortalecer los partidos de centro.

La revalorización del centro, como única opción aceptada, sobre todo por las Fuerzas Armadas, es un dato a considerar en el análisis del futuro del sistema ${ }^{58}$. El partido alternativo de centro interesa, incluso, como partido de oposición, capaz de transformarse en una alternativa de poder.

La constitución de un cuadro partidario artificial no tiene, sin embargo, grandes posibilidades de éxito. El centro ideológico no ha tenido, históricamente, en estos países, peso significativo en las últimas décadas, y no tiene condiciones para lograr el consenso mínimo necesario para garantizar la estabilidad del sistema.

En el caso argentino, todavía distante de la etapa de apertura política, aunque con una levísima descompresión observable en los últimos meses, la carta que se juega es la de los partidos federalistas y demócratas progresista, considerados "amigos del proceso", al tiempo que se planea domesticar al peronismo y cooptar parte de su dirigencia política y gremial. Como se suele decir, en política todo se relaciona con todo y todo es más complejo de lo que parece. Y la realidad social a la que estas políticas tratan de manipular suele ser poco dócil.

No obstante, las Fuerzas Armadas, dispuestas inequívocamente a institucionalizar su poder real ${ }^{59}$ han fijado límites estrictos al accionar de las fuerzas políticas ${ }^{\mathrm{BO}}$.

La liberalización no puede exceder los límites que aseguren, en forma indefinida, la aplicación de la doctrina de seguridad nacional. Los regímenes pueden ser autoritarios o democráticos pero deben ser in equívocamente controlados o semicontrolados.

Aưn en aquellos países mayores de América Latina que conservan un sistema democrático, como Colombia, la situación de debilidad del gobierno, la violencia política desatada hace ya tiempo, más una conflictiva situación social, son argumentos usados para cuestionar la eficiencia del propio sistema político y facilitar su inclinación hacia formas de democracia limitada, con participación 'creciente del poder militar.

${ }^{58}$ Son interesantes los artículos publicados en el Suplemento Especial "Brasil Partidos" del Jornal do Brasil del 5-8-79: María do Carmo Campelo de Souza, "Ovo de Colombo da engenharia partidaria", p. 3; Sergio Henrique Abranches "A politica do impasse. Democracia e Reforma partidaria", p. 5 y María Victoria Benevides "As Armadilhas do Centro", (p. 2).

${ }^{59}$ Todo el tema de la convergencia cívico-militar en Argentina gira alrededor de este tema. (Ver por ejemplo las declaraciones del Gral. Albano Harguindeguy, Ministro del Interior argentino, en Clarin, 1-7-1979).

${ }^{60}$ Jornal de Brasil, 28-9-79, p. 4. 
En estos proyectos de vigorización del centro no puede omitirse un dato que, por negativo que se lo quiera considerar, no deja de ser real y marcante. La tradición "personalista" predominante, sobre todo en los países semiindustrializados de América Latina.

Se apoya mucho más a los líderes que a las ideas y la falta de ejercicio realmente democrático es un obstáculo para el surgimiento de liderazgos nacionales.

Transportar la experiencia europea a estas tierras, como muchos pretenden significaría modificar drásticamente esa tendencia, tarea que no puede realizarse ni en diez ni en veinte años ${ }^{61}$.

Partidos de centro, o aun conservadores, pudieron funcionar adecuadamente cuando hubo un líder carismático (caso del PSK en Brasil) pero su viabilidad es muy dudosa en el presente contexto. ¿ $Y$ qué pasará con los sectores populares, ya mejor organizados, autónomos y politizados? ¿Se sentirán representados por este centro cuyos lineamientos ambiguos no dejan, sin embargo, dudas respecto de su intrínseco conservadorismo? ¿̇o por qué otro partido o movimiento? ¿Qué pasará si reinstaurado el sistema democrático, vuelven a ganar las elecciones los partidos de la oposición no confiable? El problema de estos proyectos es, entre otros, que no están dejando espacio para las fuerzas políticas y sociales reales, que permanecen vigentes detrás de toda la estructura legal e institucional, con que se trata de neutralizarla. No vale como punto de partida tratar de cambiar la idiosincrasia de esas fuerzas (sean partidos, sindicatos, etc.) para adaptarlas a un modelo político "comme il faut". No sirve, para el mediano plazo, basar la estrategia en la división de la oposición ni en la atomización o el control obsesivo del movimiento obrero, porque - dado un determinado grado de organización y politización (que ya fue alcanzando en los países semiindustrializados latinoamericanos) - la recomposición de esos grupos se producirá por su propia fuerza intrínseca, porque no hay alternativas válidas para reemplazarlos y porque, como es sabido, la agresión externa favorece la cohe-

${ }^{61}$ El fallecido Ministro de Justicia de Brasil, Petronio Portella, articulador de la apertura política, llegó a vaticinar que en dos años Brasil estaría posiblemente adoptando soluciones políticas de acuerdo con el modelo socialdemócrata consagrado en Europa, (Jornal do Brasil 13-1-80, p. 11). En Argentina el ex Comandante en Jefe e integrante de la Junta Militar, Almirante Emilio Massera, se ariesgó en un intento de nuclear fuerzas políticas alrededor de una filosofía proclamada socialdemócrata. El propio programa del partido de gobierno en Brasil (PDS) sucesor de ARENA, incorpora instituciones e ideas del mismo corte y Leonel Brizola, no obstante sus salvedades, recibió seducido las influencias de "los sectores progresistas de Europa ligados a la social democracia" y de los "sectores liberales norteamericanos". (Ver entrevista en Jornal do Brasil, 26-8-79, p. 8). 
sión. Al dejar esos "claros". en el sistema, la élite dirigente aumenta sus propios riesgos de perder el control del proceso.

Si esto es así, frente al siempre enunciado propósito de restaurar la democracia, uno puede preguntarse, con $\mathrm{O}^{\prime}$ Donnell ${ }^{62}$ ¿Qué democracia?

Evidentemente, una poco ortodoxa que excluya el verdadero debate ideológico y en la que las élites dirigentes se reserven el control incuestionado de todas las variables esenciales.

Como es nuestro convencimiento que en estos países ninguna de las opciones políticas ya intentadas está realmente "fagotada", el sistema artificial que se gesta lleva implícito un grado-considerable de inestabilidad.

Los sectores populares excluidos —aún en el caso en que están más organizados- no se transformarán a la social democracia ni se adecuarán a moldes "laboristas", tipo inglés, en el curso de unos años, y desde la periferia del sistema político ejercerán sobre el Estado autoritario presiones que éste no está preparado para responder en forma institucional.

La clase media y el empresariado nacional, por su parte, que suelen ser los primeros en cuestionar el sistema democrático que los deja a merced de la "amenaza" proveniente de la clase obrera, no ha tardado nunca demasiado en advertir que las políticas económicas ortodoxas los debilitan como clase y los subordinan a los intereses privilegiados del sector financiero, la gran industria, el capital internacional y la burocracia estatal.

Del entusiasmo inicial se deslizan hacia la oposición y quedan finalmente otra vez disponibles para sostener programas de corte más desarrollista o nacionalita.

Faltas del consenso de estos sectores vitales, las élites, liberales en lo económico y autoritarias en lo político, representantes del "liderazgo modernizante" de los países semiindustrializados de América Latina, tienen escasas posibilidades de lograr el sistema democrático, orgánico, eficiente y moderno que visualizan. Precisamente, porque al analizar los presupuestos de los que parten y los proyectos que elaboran uno tiene la impresión de que no se refieren a las sociedades concretas que conocemos.

Sintetizando lo dicho, podríamos enunciar algunas observaciones que lejos de ser conclusiones son puntos de partida de futuros análisis.

a) Los páses mayores latinoàmericanos que se perciben a sí mismos como potencias intermedias, capaces de ganar espacio y mayores márgenes de maniobra en el actual sistema internacional no están, ni pueden es-

${ }^{62}$ Guillermo O'Donnell, "Tensiones...", p. 31. 
tarlo, comprometidas con los auténticos reclamos de un NOEI, provenientes del Tercer Mundo. En forma coordinada, sus grupos dirigentes están abocados a la readaptación de las economías nacionales, a estrategias de desarrollo basadas en la mejor inserción de la economía mundial, a partir de sus recursos naturales abundantes y de economías abiertas y competitivas a nivel internacional ${ }^{63}$.

b) Esa estrategia económica, que impone una política concentradora de ingresos y privilegia la gran industria privada (nacional y extranjera) supone algunos prerrequisitos políticos, toda vez que no se ha revelado compatible con la vigencia de una democracia pluralista auténtica.

Contrario de lo que suele decirse, el manejo de la economía no está condicionado por las exigencias de la ampliación del sistema político sino que esta ampliación encuentra sus límites en el punto en que la apertura ya no permite asegurar la implementación del modelo económico propuesto. La ortodoxia económica, revalorizada por los regímenes políticos de los países mayores, es perfectamente ajustable a la idea del nuevo orden internacional de los países industrializados, que reclaman una economía mundial, abierta y libre donde funcionen sin distorsiones las leyes del mercado (al margen de sus propias violaciones de estas leyes) y que alientan una nueva división internacional del trabajo en las que los NICS (Newly Industrializing Countries) pueden jugar un rol muy funcional en la estrategia de las empresas transnacionales, sobre todo en el sector de la agroindustria y de la industria manufacturera de bienes primarios.

Este modelo de desarrollo tiene los rasgos del desarrollo extrovertido, al que cíclicamente hemos vuelto en las últimas décadas.

Hay algunos aspectos, como el tratamiento a las exportaciones, sobre todo las de productos no tradicionales, que presentan diferencias significativas entre un caso y otro ${ }^{64}$. Pero básicamente, sobre todo en la primera etapa, se trata de la aplicación de un neo-laisser-faire inspirado en la muy cuestionada "escuela de Chicago".

\footnotetext{
${ }^{63}$ Sobre este punto nos remitimos a lo dicho en nuestro trabajo citado "América Latina, hacia qué nuevo orden internacional".

${ }^{64} \mathrm{Un}$ aspecto interesante es el manejo de la política arancelaria como instrumento de apertura de la economía y de diseño de la política industrial. En este aspecto el caso argentino, a partir de 1976, parece ser de los más drásticos y ortodoxios. Durante 1976 y 1977 la estructura arancelaria argentina se modificó sustancialmente. Entre octubre de 1976 y diciembre de 1977 el promedio ponderado de las tasas de protección legal con terceros países, pasó del $93,7 \%$ al $52,7 \%$ lo que representa una caída de 41 puntos, que es un caso único en la historia tarifaria argentina (cf. Julio Nougués, "Protección nominal y efectiva: Impacto de las reformas arancelarias durante 1976-1977", en Ensayos Económicos $\mathrm{N}^{\circ}$ 8, diciembre-1978, $2^{\circ}$ parte, Buenos Aires, Banco Central de la República Argentina.
} 
c) Para asegurar la consecución de estas políticas económicas en un plazo razonable y en condiciones de estabilidad, se requiere un sistema político con un. alto contenido autoritario que mantenga excluidos a los sectores populares, e incluso a sectores medios y burgureses perjudicados por el modelo.

Para evitar las tensiones máximas, a las que estos regímenes estuvieron sometidos en el pasado (por ej. el gobierno de Onganía) se consiente en "liberalizarlos" sin perder el control de las fuerzas interactuantes. Para conseguir este objetivo. se procura reformular, sobre todo, el sistema partidario, e institucionalizar la presencia militar en el sistema político.

Nuestra hipótesis es que en el presente estado de desarrollo político de los países de América Latina, este esquema no deja espacio a los grupos. más significativos y mayoritarios que, privados de alternativas, volverán a presionar exitosamente, desestabilizando los regímenes basados en forma más o menos sutiles de democracia restringida o autaritarismo flexible.

d) La variable esencial en este proceso de consolidación/desestabilización del régimen autoritario pasa por la reacción del movimiento obrero. Este tema, que será motivo de un futuro trabajo, reviste una importancia especial porque el control del movimiento obrero es el primer blanco de los gobiernos autoritarios y el sector donde el intervencionismo del estado autoritario es más intenso y duradero y porque las más serias amenazas a los regímenes autoritarios provienen del movimiento obrero organizado.

e) Finalmente, y sin dejar de reconocer algunas secuelas traumáticas dejadas - sobre todo en la clase media- por los últimos y frustrados gobiernos populistas, creemos que los países que nos ocupan no han superado el círculo vicioso que describe Huntington entre el modelo populista y el modelo tecnocrático, y recorrerán todavía un largo camino hasta lograr implementar un sistema democrático capaz de responder a los serios desafios planteados por sociedades relativamente complejas, semiindustrializadas y politizadas que al mismo tiempo necesitan resolver acuciantes problemas económicos y sociales. 